\title{
Congressional modification of benefit-cost analysis as a vehicle for particularized benefits and a limitation on agency discretion: the case of the federal contract tower program
}

\begin{abstract}
The literature on Congressional control of the bureaucracy has examined how members of Congress pursue strategies such as oversight, the limitation of discretion in legislation [Moe, T. (1989). The politics of bureaucratic structure. In J. E. Chubb \& P. E. Peterson (Eds.), Can the Government Govern? Washington, DC: Brookings Institution); Huber, J. D., \& Shipan, C. R. (2002). Deliberate discretion: The institutional foundations of bureaucratic autonomy. New York: Cambridge University Press], and the use of tools such as administrative procedures [McCubbins, M., \& Schwartz, T. (1984). Congressional oversight overlooked: police patrols vs. fire alarms. American Journal of Political Science, 21(1), 165-179; McCubbins, M., Noll, R., \& Weingast, B. (1987). Administrative procedures as instruments of political control. Journal of Law, Economics, and Organization, 3, 243-277] and limitation riders [MacDonald, J. A. (2010). Limitation riders and congressional influence over bureaucratic policy decisions. American Political Science Review, 104 (November), 766-782] to exert influence over executive agency decision making. One area where Congress has attempted to exert control over agency decision-making is through the legislative modification of one of the most common bureaucratic decision-making tools: benefit-cost analysis (BCA). While scholars have examined political influence in agency regulatory impact analysis BCAs for proposed rules [Shapiro, S., \& Morrall III, J. F. (2012). The triumph of regulatory politics. Benefitcost analysis and political salience. Regulation and Governance, 6(2), 189-206], there has been a lack of examination of Congressional modification of agency BCA processes to justify and protect particularized [Mayhew, D. (1974). Congress: The electoral connection. New Haven, CT: Yale University Press] infrastructure projects in their districts. This paper will examine the effect of Congressional control over agency BCA processes to secure particularized benefits by developing an in-depth case study of the Federal Contact Tower Program (FCTP) operated by the Federal Aviation Administration (FAA) that examines the political and public management implications of Congress's limitation of the FAA's autonomy to operate the FCTP under current benefit-cost guidance. Building upon the literature on particularized benefits and Congressional delegation, the results of this study indicate that members of Congress use BCA processes to insulate infrastructure projects in their districts by restricting the ability of agencies to optimize program effectiveness.
\end{abstract}


Keywords: agency discretion; particularized benefits; transportation infrastructure; Congress.

*Corresponding author: Russell W. Mills, PhD, Assistant Professor, Department of Political Science, Bowling Green State University, 124 Williams Hall, Bowling Green, OH 43403, USA, e-mail: millsrw@bgsu.edu

\section{Introduction: Congressional delegation of policy-making to agencies}

One of the most important areas of study within the field of political science is the examination of how and when elected officials in modern legislatures delegate policy-making authority to bureaucratic agencies, which have greater capacity to develop policy solutions to "wicked" public problems than their legislative principals (Epstein \& O'Halloran, 1999; MacDonald, 2010). A key component of the discussion around delegation of legislative policy-making functions to the executive branch has centered on how and when Congress grants discretion to agencies to implement policy and the strategic or "deliberate" reasons behind the legislative branch's delegation of power (Huber \& Shipan, 2002).

Additionally, many scholars have vigorously debated the most effective accountability mechanisms to ensure that Congress's legislative intent or policy goals are reflected in the implementation of laws by unelected bureaucrats (Huber \& Shipan, 2002; McCubbins, 1999). Scholars have detailed a variety of tools used by Congress to ensure public accountability including control through the appropriations process and limitation riders on appropriations bills (Kiewiet \& McCubbins, 1991; MacDonald, 2010), oversight through hearings or audits (Aberbach, 1990), the use of organized interest groups to draw attention (or pull the "fire alarm") to implementation issues (McCubbins \& Schwartz, 1984), the use of administrative procedures during the rulemaking process to allow for influence from organized interests (McCubbins, Noll, \& Weingast, 1987) and the reliance on agency reputation to guide legislative or changes to agencies' underlying authority (Carpenter \& Krause, 2011).

While these political science oriented studies of bureaucratic control of unelected public administrators have been very influential in outlining the conditions when Congress will delegate authority and when they will use tools to engage in oversight, they are glaringly weak in describing what executive agencies actually do with the discretion they are given (Krause, 2010). As Moe (1989) famously notes, "Bureaucrats will therefore have a measure of autonomy, perhaps a substantial 
measure - and they can use the coercive power of public authority to pursue their own interests at the expense of their creators" (p. 234). The field of public administration has focused more on what agencies do with the grant of discretion from Congress, but has not focused on the conditions where this delegation is expanded or restricted. Krause (2010) argued that in order to bridge the gap between political science and public administration delegation literatures, the "third generation" of delegation research should "provide a richer portrait of hierarchical relations within the executive branch between presidents and administrative agencies" and determine how and why Congressional delegation of policy-making authority makes a difference in the effectiveness of the implementation of the policy.

One area where Congress has attempted to exert control over agency decision-making is through the legislative modification of one of the most common bureaucratic decision-making tools: benefit-cost analysis (BCA). BCA is a tool used by agencies to justify regulations, operational programs, and infrastructure investments (GAO-05-423SP). The scholarly debate over the use of BCA by agencies has focused primarily on the use of BCA for assessing the benefits and costs of new regulations through regulatory impact assessments (RIAs) conducted through the Office of Information and Regulatory Affairs (OIRA) (Kerwin and Furlong, 2011; Yackee \& Yackee, 2010). The uncertainty of both the conceptualization and measurement of both costs and benefits used in RIAs have also been debated by scholars, both from a technical (Ellig, McLaughlin, \& Morrall, 2012; Heinzerling, 1998; \& Sen, 2000) and normative (Copp, 1987; Kelman, 1981; Revesz \& Livermore, 2008) perspective. However, as Shapiro and Morrall (2012) note in a recent article, the literature on BCA largely minimizes the importance of the political climate in which such analysis is done and the implications of this relationship. While these studies begin to examine the intersection of politics and BCAs used to justify regulations, they ignore the influence of politics in the use of BCAs by agencies to justify and prioritize infrastructure investments and program operations. In agencies that use BCA to allocate both infrastructure projects and operational programs (such as the Department of Transportation), members of Congress can exert substantial influence over agency decision-making and, in certain circumstances, can make statutory modifications to agency BCA processes to ensure that distributive particularized benefits (Mayhew, 1974) such as local transportation infrastructure are retained or built in specific districts.

This paper will examine the effect of Congressional control over agency BCA processes by developing an in-depth case study of the Federal Contract Tower Program (FCTP) operated by the Federal Aviation Administration. The FCTP provides air traffic control services and infrastructure at airports with lower activity levels. With 252 towers in 48 states, the FCTP is an excellent example of a distributive program that is beneficial to members of Congress (local infrastructure, 
local jobs, etc.). Using document analysis, Congressional testimony, and personal reflections and observations of the author (a former FAA employee working on the FCTP), this paper will develop a rich case study of the FCTP that examines Congress's delegation to establish the program, how the FAA and other executive actors responded by implementing the program, the mechanisms and tools used by Congress and various interest groups to oversee how the FAA implemented the program, and finally how Congress's oversight of the FAA's process for implementing the FCTP has impacted the effectiveness of the program. The case study will be analyzed and extrapolated to examine larger theoretical issues in the areas of Congressional delegation and particularistic policymaking such as the how members of Congress can use BCA modifications to both expand a beneficial particularistic program while also insulating and protecting particularistic benefits already in a district. Additionally, this paper addresses how the political environment of BCAs can affect the quality of the decision-making by agencies (Shapiro \& Morrall, 2012) and can limit the ability of an agency to optimize and prioritize its resources.

\section{The use of BCA by the executive branch}

Benefit-cost analysis (BCA) is a tool used to aid public investment and regulatory decisions by measuring the efficiency of spending from the viewpoint of net benefit to society. The typical BCA process involves four steps:

- Identify the positive aspects (benefits) and negative characteristics (costs) of a project or action

- Monetize each of the values over a determined time-horizon and portray them on an equal basis by calculating the present value of costs and benefits (achieve through discounting)

- Calculate the net present value (or benefit-cost ratio) from combining all of the benefits and costs.

- Make a decision based on the benefit-cost ratio (B-C ratio) (i.e., If the $\mathrm{B}-\mathrm{C}$ ratio is above 1.0, the proposal satisfies the Kaldor-Hicks Criterion and an agency should take action either by issuing a regulation or by building a piece of infrastructure).

Landau and Weisbrod (2009) note that BCA can guide policy by answering the following questions:

- Do the economic benefits of an action justify its economic cost?

- This question typically focuses on a single project or program, although it can extend to a group of related projects. The key concept here is whether a project would be undertaken at all based on economic criteria. 
- Which project, among a number of scheduled projects, should be completed first?

- Because BCA considers costs and benefits over time, it can be used to prioritize among a number of competing demands for government resources, identifying those that, at present, offer the best "return" on investment.

- When should a project be undertaken?

- For some projects or actions, optimal timing may depend on forecasted changes over time in such factors as market growth in demand for the facilities or services, or relative shifts in funding and construction costs. BCA can consider how project timing affects the relative efficiency of investments.

BCA has traditionally been used by executive agencies to maximize scarce resources to provide public goods through a variety of mechanisms including regulations through rulemaking, public infrastructure projects, and public program operations. At the federal level, the use of BCA is overseen by the Office of Management and Budget $(\mathrm{OMB})$, which is responsible for coordinating regulatory activity, the development of the federal budget, and executing the government-wide management agenda. OMB produces guidance that outlines how agencies will conduct BCA for regulatory impact assessments (OMB Circular A-4) and for programmatic and infrastructure decisions (OMB Circular A-94). The OMB Office of Information and Regulatory Affairs (OIRA) is responsible for overseeing agency regulatory impact assessments (RIAs) and ensuring that the benefits of agency regulations justify the costs and that the alternative selected maximizes the benefits to society. On the budget side of the OMB house, program examiners in Resource Management Offices (RMOs) are responsible for developing, reviewing and clearing budget proposals, legislative proposals, Congressional testimony by agency officials, and for reviewing key pieces of analysis produced by agencies (Johnson, 1989; Tomkin, 1998). Each examiner is responsible for ensuring that the budget resources authorized and appropriated to the agency under their control are spent in accordance with both statutory language but also the President's budgetary priorities (Tomkin, 1998). The next section details the three primary uses of BCA in federal agencies: regulatory impact assessments, public infrastructure projects, and program operations.

\subsection{Regulatory impact assessments}

Examinations of the impact of proposed regulations, known as regulatory impact assessments, have their roots in the Nixon Administration's “Quality of 
Life" reviews of regulations from the newly created Environmental Protection Agency (EPA) and the Occupational Safety and Health Administration (OSHA) (Weidenbaum, 1997). President Ford expanded this interagency review process to include all agencies by signing Executive Order 11,821, which mandated that an Inflation Impact Statement (IIS) be submitted with all major regulations (McGarity, 1991). The seminal moment in the history of the use of BCA for regulatory review occurred in 1981 when the Reagan Administration issued Executive Order 12,291, which required agencies to refrain from taking regulatory action "unless the potential benefits to society for the regulation outweigh the potential costs to society and prepare a "regulatory impact analysis" for each "major" rule, which was defined as any regulation likely to result in (among other things) an annual effect on the economy of \$100 million (CRS Report, 7-5700; McGarity, 1991). The major component of the regulatory impact analysis is a BCA that weighs the quantified costs and benefits (typically quantified through number of lives saved through a particular action) of the proposed rule. Today, almost every agency that issues rules conducts BCAs on economically significant rules to examine the proposed costs and benefits of a regulatory action.

Much of the scholarly literature on the use of BCA by agencies has focused on assessing the technical accuracy of estimating costs and benefits of regulations proposed by agencies (Kerwin \& Furlong, 2011; Sen, 2000). Heinzerling (1998) found that many costs and benefits contained in RIAs could not accurately be quantified, particularly because BCA improperly discounted future lives. In a wide-ranging study of regulations in both the Bush and Obama Administrations, Ellig et al. (2012) found that agencies more central to an administration's policy priorities do not have to produce as good an analysis to get their regulations promulgated. Scholars have also examined the impact of RIAs on regulatory delay, which Kerwin and Furlong (2011) note has been identified as a significant problem by many in Congress. Yackee and Yackee (2010) assert that contrary to popular opinion procedural constraints on rulemaking such as RIAs do not interfere with the ability of agencies to act in a timely manner.

Other scholars have conducted normative evaluations of BCA in the rulemaking process. Kelman (1981) famously questioned whether it is appropriate to quantify some benefits such as attaching values to human life. Copp (1987) contended that BCA led to greater divisions in society by favoring the wealthy over the poor. Heinzerling (1998) noted that many costs and benefits could not accurately be quantified, particularly because BCA improperly discounted future lives. Challenging the findings of those critical of BCA, Revesz and Livermore (2008) and Sunstein (2011) argue that RIA BCAs lead to more transparent and democratic decision-making by agencies. While there is a substantial literature on the context and effect of the use of BCA to assess regulatory actions, the scholarly 
literature on the use of BCA to assess public infrastructure programs and program operations is much less developed.

\subsection{Public infrastructure projects}

While the modern application of BCA in the US has been primarily associated with regulatory or policy appraisal through RIAs, the historical origins of BCA in the US lie in infrastructure investment decisions. BCA in the US had its roots in decisions made by the Army Corps of Engineers regarding where and when to place dams along rivers (Porter, 1996; Zerbe, 2007). Prior to the Corps outlining its criteria in 1902, almost all investment decisions had been made on an ad hoc basis. The Flood Control Act of 1936 mandated what the Corps had already been practicing: in order for a proposed infrastructure project to move forward, the benefits of a project had to exceed the expected costs. Initially, the reliance on BCA to justify and prioritize infrastructure projects insulated the Corps from political pressure from members of Congress and interest groups. However, during 1940, the Corps came under fire from Congress, other Federal agencies and the electronic and railroad utilities for failing to rely of principles of economics such as discounting in their BCA (Zerbe, 2007). The push for greater reliance on economic principles in BCA led to conflict within the Corps and the expansion of BCA as a justification for government action across states, localities, and particularly at the Federal level through RIAs. Most importantly, however, the push by Congress and others to fundamentally alter the Corps' analysis process was the first step toward Congressional influence in the calculation of BCAs. While several agencies conduct BCAs for regulatory impact analysis, a fewer subset conduct BCAs to determine if federal dollars should be spent to provide infrastructure in a local area. The most predominant area where such BCAs are conducted is in the area of transportation infrastructure investments such as roads, bridges, airports, and air traffic control towers.

Much of the scholarly examination of BCAs for infrastructure projects has focused on critiquing the process for conducting the BCAs outlined in OMB Circular A-94. The purpose of OMB Circular A-94 is "to promote efficient resource allocation through well-informed decision-making by the Federal Government. It provides general guidance for conducting benefit-cost and cost-effectiveness analyses” (OMB Circular, A-94, p. 2). Goldberg (1998) critiqued the discount rate for long-term federal projects and found that a variable discount rate resulted in more sound analysis to guide agency decision-making. In a thorough review of the use of BCAs for federal transportation infrastructure investments, Lee (2005) 
argues that while many federal officials believe that BCA is the preferred framework to evaluate infrastructure proposals, the development and refinement of BCA processes has lagged behind the enthusiasm. Other studies have examined how agencies can use BCAs to advocate for infrastructure projects viewed by the agency as priorities that have proven not to be cost-beneficial in ex post evaluations of the project (Flyvbjerg, 2009; van Wee, 2012).

\subsection{The use of BCA for program operations}

A largely unexplored area of research is an examination of the use of BCA to justify and prioritize the continued operation of a federal program. In an increasingly constrained budget environment, agencies are under pressure to make cuts in programs that are not producing results. Moreover, as agencies look to implement across-the board cuts as a result of the sequester mandated by the Budget Control Act of 2011, BCA offers a way to evaluate programmatic operations at the site level to optimize agency spending of scarce budget resources. Lee (2005) argued that because of the prevalence of BCA for the justification of federal transportation projects, the tendency among many elected officials and localities has been to ignore or largely devalue the operating costs of a long-term project to ensure the capital project is cost-beneficial. There remains a significant gap in the benefit-cost literature on the inclusion of operating costs of public infrastructure projects, particularly as agencies try to optimize shrinking operations and capital budgets. This paper will address this gap by exploring the use of BCA to justify the continued operation of air traffic control towers under the Federal Contract Tower Program.

\section{$3 \mathrm{BCA}$ and congressional delegation}

While many previous studies provide important evaluations of the use of BCA, they are noticeably scant in their treatment of the strategic use of BCA by members of Congress as a mechanism of control of bureaucratic agencies. In their seminal article, McCubbins et al. (1987) famously examine the use of processes mandated under the US Administrative Procedures Act of 1946 (APA) to control bureaucratic decision-making. The APA established a series of ex ante, or fire alarm (McCubbins \& Schwartz, 1984), mechanisms of oversight including notice and comment periods, hearings, and requirements for the agency to provide a link between the evidence presented and their decisions (McCubbins et al., 1987). However, arguable most importantly, the APA established the framework for RIA BCAs, which 
are also an ex ante method of control of agencies by members of Congress. Posner (2001) notes that the purpose of requiring agencies to perform BCA on rules is not to ensure that regulations are efficient; it is to ensure that "elected officials maintain power over agency regulation” (p. 4). Kochtcheeva (2009) develops an in-depth case study of the influence of both Congress and the courts in limiting the discretion of the Environmental Protection Agency (EPA) to promulgate rules. In describing the use of BCA to evaluate programs, Lee (2005) argues that members of Congress often call for BCA to be applied to programs they support in order to provide an "objective" evaluation of the cost-beneficialness of the program they support. This suggests that BCAs may be a tool used both by Congress and agencies in the delegation dilemma: members of Congress may legislate changes to internal agency BCA processes to control agency behavior while agencies may use their expertise of a policy area to make subtle yet important changes to BCA calculations in an attempt to pursue a desired policy outcome. A recent study of RIA BCAs that examined the benefits of rules promulgated by agencies found that the rules in the most political environments (measured by the number of public comments) were often the least net beneficial to society while those in the least political environments were most beneficial (Shapiro \& Morrall, 2012). This paper expands upon Shapiro and Morrall's work by considering the strategic use of BCA as a tool by members of Congress to influence internal agency decision-making related to the placement and priority of infrastructure projects and the continued operation of a program with particularized benefits (Mayhew, 1974).

\section{Particularistic policymaking and BCA}

Many studies have examined the institutional conditions of Congress, the White House, and agencies that lead to a greater flow of particularized benefits to Congressional districts. Mayhew (1974) famously claimed that members of Congress pursue their reelection incentive by engaging in credit claiming for particularized benefits or distributive public goods (Lowi, 1964) brought back to the district. As Fiorina (1989) also noted:

Federal projects are highly visible and their economic impact is easily detected by constituents. The average constituent may have some trouble translating his Congressman's vote on some civil rights issue into a change in his personal welfare. But the workers hired and supplies purchased in connection with a big federal project provide benefits that are widely appreciated (Fiorina, 1989, p. 40).

Other scholars have investigated the assumption that members of Congress demand more particularized benefits as the local cost of these projects decreases. 
DelRossi and Inman (1999) found that as the local cost-share for water-infrastructure projects increased, the demand for these public projects from members of Congress decreased substantially. Finally, scholars have also examined how agencies manage competing demands from members of Congress for local infrastructure projects.

Much of the political science literature on distributive policies has focused on the determinants and expansion of agency allocation of infrastructure and operational programs (commonly referred to as pork barrel projects). Arnold's (1979) study of the Department of Housing and Urban Development's Model Cities program found that the agency used the program to build support for the agency's mission by allocating Model Cities grants to districts whose members had voted for increased appropriations for the agency. Shepsle and Weingast (1981) argue that the legislative logrolling for votes on distributive policies results in the benefits for these programs becoming quasi-universalistic. Bickers and Stein (1994a, 1996) empirically test the universalistic nature of distributive benefits and find little evidence of the universalism hypotheses. The authors argue that rather than focusing on the flow of benefits to their districts, members of Congress may attempt to provide support for key interest groups through mechanisms (changes in allocation formulas, changes in program requirements, etc.) other than programmatic benefits. Therefore, by showing support for a distributive program without receiving the direct benefit of that program, the interest groups supporting the program will provide "credit claiming" support for the member in his district and at the federal level. In a more recent study, Bertelli and Grose (2009) examined grants from the Department of Labor and contracts from the Department of Defense and found that the allocation of projects was contingent on the ideological congruence between the department making the allocations and the senators representing the states receiving distributive benefits.

Much of the literature on particularistic policymaking has focused on examining the outcomes of Congressional interaction in agency allocation of distributive benefits through appropriations earmarks, grant making, or other direct lobbying mechanisms. However, there is a lack of examination of how Congress can indirectly affect internal agency decision-making related to the placement and priority of infrastructure projects and operational programs with particularized benefits by modifying and prescribing agency BCA processes. This paper will add to the literature on particularized benefits and Congressional delegation by examining the how members of Congress use specific modifications to agency BCA processes to insulate and protect distributive infrastructure projects while also reducing agency discretion in optimizing program effectiveness. Through the development and analysis of the case of the Federal Aviation Administration's (FAA) Federal Contract Tower 
Program (FCTP), this paper will examine how members of Congress use modifications to BCA to justify requests for new infrastructure projects while also protecting existing infrastructure projects that may not be cost-beneficial to society.

\section{Data and methods}

This paper will develop a rich and detailed case study of the legislative history and the evolution of BCA practices within the FCTP. Specifically, this single embedded case study (Yin, 2003) will provide insights into the modification of BCA by Congress to enhance and protect particularized benefits while also limiting the ability of agencies to optimize their programmatic resources. The 30-year history of the FCTP, the highly political nature of the program, the reliance on BCA to guide agency decision-making, and the highly distributive nature of the benefits provided by the program make this case an appropriate one to examine for this study. The case study will be built using source documents including internal FAA memos, agency guidance, internal orders, GAO reports, DOT-IG reports and agency research reports. Additionally, the case study will be supplemented by personal notes and observations of the author, who was a Policy Analyst at the FAA from 2010 to 2012 and was responsible for conducting BCAs for the FCTP. The data will be analyzed by through an open-coding content analysis that develops a rich description (Geertz, 1973; Gibbs, 2007) of the evolution of both the FCTP and the BCA process within the FAA. Scholars in the fields of political economy (Alston, 2005) and public administration (Jensen \& Rodgers, 2001) have noted the "intellectual gold" (Jensen \& Rodgers, 2001) of case study research in illustrating the "patchworked" nature of the longitudinal evolution of policy programs and regulatory regimes.

\section{Federal contract tower program}

\subsection{The FAA and air traffic control}

The Federal Aviation Administration (FAA) is the primary government agency responsible for regulating aviation in the US. In addition to serving as a regulatory agency, the FAA is also the operational provider of air traffic control services and is responsible for secure and efficient air traffic management services and aeronautical information to customers operating in the national airspace system. In addition to the 264 air traffic control towers operated by the FAA and 
its unionized controllers, the agency also oversees 252 towers operated by private contractors through the Federal Contract Tower Program (FCTP). Under the FCTP, the FAA can contract with private entities to provide air traffic control services at airports operating under visual flight rules (VFR) ${ }^{1}$ that did not formerly have a tower or wanted to convert a former federal tower to a contract tower. These airports tend to be in smaller communities, have little commercial service, and less complex airspace than at larger airports. However, the presence of a tower in these smaller communities typically has an impact on the local economy through the jobs created by the tower and increased activity at the airfield (USCTA, 2011). In order to determine if the agency can enter into a contract with a private contractor, the FAA's Office of Policy and Plans (APO) conducts a BCA to determine if the societal benefits (both efficiency and safety) generated by the insertion or conversion of a tower are greater than the societal costs associated with operating the tower. While it has been recognized by the Department of Transportation Inspector General (DOT-IG) as a cost saving program, the FCTP has been controversial largely due to labor issues related to the scope of appropriate expansion of the program and due to modifications to the BCA process throughout the history of the program.

\subsection{Legislative origins of the FCTP}

The Federal Contract Tower Program (FCTP) was created by the Tax Equity and Fiscal Responsibility Act (P.L. 97-248) on September 3, 1982 (Figure 1). The FAA implemented the statute by creating a pilot program to contract for air traffic control services for five level I towers (low-level towers) that were closed as a result of the Professional Air Traffic Controllers Organization strike in 1981. While the stated goal of the FCTP was to increase efficiency and to reduce operating costs at air traffic facilities, Congress endorsed the contracting out of towers primarily as a means to reopen the temporarily closed towers. Following the contracting of the five previously closed towers, Congressional authorizers and appropriators continued to expand the program to include other closed towers by including language in appropriations and authorization bills that directed the FAA to open contract towers in specific communities while also containing a limitation rider that directed the agency not to close any currently open contract towers (DOT Memo, 1986). This led to the expansion of the number of contract

1 VFR towers do not use radar to separate aircraft and instead rely on visual and voice communication to sequence and separate aircraft. 


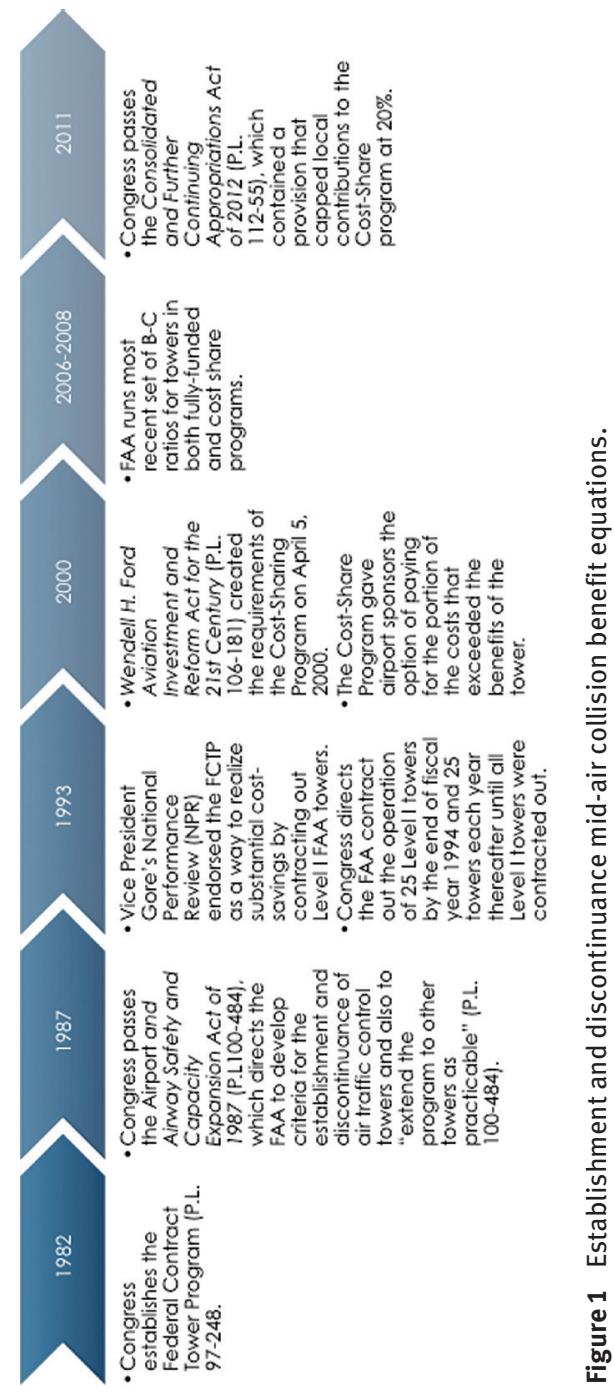


towers from 5 in 1982 to 17 in 1986. In 1986, the FAA recommended to the Secretary of Transportation and to Congress to end the FCTP due to the high one-time insurance and equipment costs associated with contracting an air traffic control tower. While not required by existing statute, the FAA conducted BCAs on each of the 17 towers in the program to justify the lack of efficiency in contracting these towers. From the BCA, the FAA showed that only one of the 17 contract towers was cost-beneficial (DOT Memo, 1986). Despite the FAA's recommendations, Congress passed the Airport and Airway Safety and Capacity Expansion Act of 1987 (P.L. 100-484), which directed the Secretary of Transportation develop criteria for the establishment and discontinuance of air traffic control towers and also to "extend the program to other towers as practicable" (P.L. 100-484).

\subsection{The evolution of the BCA process}

In 1983, the FAA revised its BCA criteria in APO-83-2 (Establishment and Discontinuance Criteria for Airport Traffic Control Towers) by calculating B-C ratios using site-specific traffic forecasts to determine benefits and costs. Specifically, the FAA's Terminal Area Forecast (TAF) would be used to determine site-specific traffic projections at airports, which would then be applied to the nationally calculated factors for accident avoidance and efficiency-related benefits. This modification gave the FAA much more insight into which of its towers were cost-beneficial. Many airport managers were not happy with the criteria passed initially in APO 83-2 because the BCA contained a built-in advantage for those airports with large aircraft based at their field. The Airport and Airway Safety and Capacity Expansion Act of 1987 (P.L. 100-484) contained two provisions that directly impacted the FAA's BCA process:

- Section 308 directed the FAA to develop criteria for the establishment and discontinuance of towers by promulgating rule making. This had previously been done via internal FAA orders and would allow interested parties to have influence into how the FAA would conduct its BCA process for air traffic control towers.

- Section 308 also contained a number of specific requirements for the FAA's final rule on its BCA process, including requirements to consider traffic density at airports without regards to aircraft size, terrain and other obstacles to navigation, weather characteristics, and aircraft operating efficiencies, all of which were not included in APO 83-2.

The precursor to rule-making was the issuance of APO 90-7 (Establishment and Discontinuance Criteria for Airport Traffic Control Towers) in 1990. APO 90-7 
implemented the Congressionally mandated modifications to the BCA process outlined in P.L. 100-484 while also updating the safety and efficiency factors used to calculate the site-specific benefits of an air traffic control tower. Specifically, APO 90-7 was based largely on a study that examined accident rates at two sets of airports-those with air traffic control towers and those without towers. There were several important outcomes of APO 90-7. First, the agency felt it had a rigorous way to examine its internal operations. While the agency had conducted BCAs on its own towers in the past, there was a feeling that the results were more advisory than actionable given the lack of rigor in the methodology. APO 90-7 allowed the FAA to move forward with conducting routine BCAs on all of its towers ("FAA Discontinues Funding of Air Traffic Control Services" 1995). More importantly, APO 90-7 allowed the FAA to examine its contract towers using the same methodology as its own towers. The updated BCA process, as well as requirement that an air traffic control tower have a $\mathrm{B}-\mathrm{C}$ ratio above 1.0 before its establishment, was codified into law on August 11, 1993 (14 CFR Part 170).

\subsection{The FAA's BCA model}

Like most federal agencies, the FAA uses BCA as a tool to maximize its budget allocations by investing in projects and programs that are cost-beneficial to taxpayers. As Congress continues to reduce overall budget levels as part of austerity measures, agencies such as the FAA are looking for areas to reduce expenditures on programmatic areas that provide marginal benefits. In the case of the Federal Contract Tower Program, the funding for the program comes from the FAA's Operations account, which provides funding to most personnel at the agency including air traffic controllers.

The FAA's BCA model is based on the analysis contained within APO 90-7. The model quantifies the relative benefit of an air traffic control tower by measuring the safety and efficiency benefits of having an air traffic control tower at an airport (outlined in Table 1). Specifically, the FAA's BCA model uses the number of annual operations at an airport and the safety factors contained in APO 90-7 to quantify the safety benefits of the tower in preventing fatalities, injuries, and costs of aircraft damage associated with accidents that can be prevented by a towermid-air collisions and accidents on the airfield (Model illustrated in Appendix A). The model also uses annual operations and the value factors for the reduction in aircraft operating time and the value of passenger time to determine the efficiency benefits of a tower. For example, the presence of an air traffic control tower at an airport could provide more efficient operations through time and fuel savings as pilots can receive information from controllers as to the traffic at an 
Table 1 Benefits of low-level air traffic control towers.

\begin{tabular}{lll}
\hline Objectives & Metrics & Sources \\
\hline $\begin{array}{l}\text { Safety - Prevent mid-air collisions } \\
\text { and accidents on airfield }\end{array}$ & $\begin{array}{l}\text { Avoided fatalities - Value of } \\
\text { statistical life } \\
\text { Avoided injuries - Medical } \\
\text { and legal costs } \\
\text { Avoided costs of aircraft } \\
\text { and property damage }\end{array}$ & DOT \\
$\begin{array}{lll}\text { Aircraft operating cost } \\
\text { Efficiency - Minimizing operational } \\
\text { cost and saving users time }\end{array}$ & FAA & DOT and industry \\
\hline
\end{tabular}

airport without the pilot having to fly over the airfield as is required at uncontrolled airfields. Next, the FAA's BCA model quantifies the operating (labor and facilities and equipment costs) and capital (construction costs) costs associated with the tower. The quantified benefits and costs are then discounted for present value over a 15-year time horizon using a discount rate of 7\% (OMB Circular A-94).

Importantly, the FAA's BCA model has two conditions under which analyses are conducted. The first condition, establishment, occurs when a local airport is requesting the construction of a new tower or the conversion of a non-federal tower (funded by local funds) to federal contract tower. Under this case, the construction costs of the new tower are included in the BCA. Also, because the FAA can evaluate the baseline safety and efficiency conditions of the airport prior to the investment of federal dollars, the BCA model uses the stricter "establishment criteria" for safety and efficiency benefits, which are estimated using the mean benefit calculations from the analysis in APO 90-7. The second condition, discontinuance, occurs when an airport currently has an operational federal contract tower. The purpose of the discontinuance analysis is to examine whether future federal investment in the operation of the tower is cost-beneficial. Therefore, because the analysis is looking at removing a tower, the discontinuance BCA includes costs associated with decommissioning the tower and for paying moving expenses for contract controllers (APO 90-7). Also, because the FAA does not have an accurate estimate on the safety and efficiency conditions of the airfield without the tower (i.e., because the tower is there, the agency cannot know the environment without the tower), the BCA model uses a set of criteria that give more credit for efficiency and safety benefits. For example, Figure 2 illustrates the equations used to calculate the mid-air collision benefit in the BCA model. The establishment criteria of 1.802 is significantly less than the 3.978 discontinuance criteria for mid-air collisions, indicating that the FAA's BCA model gives much 


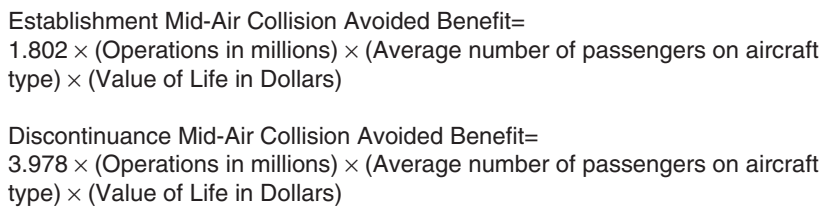

Figure 2 Timeline of key events in FCTP history.

more credit for preventing mid-air collisions to current towers than proposed towers.

Noticeably absent from the FAA's BCA are both the local jobs and economic activity created as a result of construction and operation of the air traffic control tower. The FAA's BCA model captures local direct benefits to users of air traffic control services including safety (avoided collisions, etc.) and efficiency gains from air traffic sequencing (time savings for pilots and aircraft fuel costs). The Department of Transportation's guidance on BCA (DOT, 2003) notes that agencies should not include indirect benefits of infrastructure projects or operational programs in BCAs as these are classified by OMB Circular A-94 and scholars (Lee, 2005) as economic transfers and are not considered in decisions related to federal infrastructure or program decisions. Local jobs created from federal investment in infrastructure projects or operational programs such as air traffic control are not considered as benefits because the jobs created under one project or program investment in a location would still be created if the project or program were put in another community. The DOT guidance encourages agencies or local governments to conduct economic impact assessments of federal investments to determine the indirect benefits of infrastructure projects and program investments such as job creation or increased economic activity.

\subsection{The national performance review, congressional action, and the expansion of the FCTP}

Using the criteria contained in APO 90-7, the FAA conducted BCAs of all its towers in 1992 and found that 35 of its Level I towers were not cost-beneficial. The agency recommended closing 23 of these towers and planned to close another 12 . The closing of the additional 12 towers was met with resistance from specific members of Congress who had suggested converting these FAA towers to contract towers (GAO 94-265). As of 1992, the FAA had established 27 contract towers-7 were FAA towers that had been temporarily closed due to the PATCO strike, 1 was a former FAA tower that was converted to a contract tower, and 18 were specific Congressional requested towers in appropriations bills. The FAA noted that while it sup- 
ported the FCTP "to the extent that the program permits the FAA to utilize its limited resources in the most efficient manner," the Congressional "place-naming" of FCTP sites that did not meet the B-C requirements led to inefficiencies in the program (FAA Memo, 1992).

In 1993, Vice President Gore's National Performance Review (NPR) endorsed the FCTP as a way to realize substantial cost-savings by contracting out Level I FAA towers. In its report, the NPR found that if the FAA contracted out all 99 of its Level I towers, it would save $\$ 20$ million annually in operating costs due mainly to the fact that contract controllers would not be Civil Service employees and could be paid substantially less than their FAA controller counterparts. Congress, already having a favorable view of the program, took action to expand the FCTP in the Department of Transportation and Related Agencies Appropriations Act of 1994 (P.L.103-122) by directing the FAA to contract out the operation of 25 Level I towers by the end of fiscal year 1994 and 25 towers each year thereafter until all Level I towers were contracted out. P.L. 103-122 also directed the FAA to use BCA to close its most non cost-beneficial towers. The FAA worked with the National Air Traffic Controllers Association (NATCA), which was opposed to Congress's plan to contract Level I towers, to determine the first 25 sites to be contracted out (GAO 94-265).

By the end of 1994, the FAA's newly created Federal Contract Tower Program Office (FCTP Program Office) awarded four national contracts to three air traffic contractors based on geographical areas corresponding to FAA regions. The FCTP Program Office was responsible for converting 25 Level I towers per year to contract towers and to contract all 100 Level I towers by FY 1997. However, during the process of contracting out the existing Level I towers, members of Congress pressured the Program Office to accept applications from airports who did not have existing towers on their airfield. Under this process, the airport sponsor would submit an application to the FCTP Program Office, which included not only O\&M costs but also costs for the construction of a brand-new air traffic control tower (under the establishment criteria mentioned earlier). The approval of new starttowers coupled with the contracting out of all Level I towers led to the explosion of the program from just 27 towers in 1992 to 160 towers at the end of 1997 (DOT-IG 98-147). Importantly, in 1997, the American Association of Airport Executives (AAAE) created the US Contract Tower Association (USCTA) to advocate on behalf of airports with contract towers in Congress. The first success of the USCTA was to secure a line-item appropriation in the 1998 Department of Transportation Appropriation Act that included funding of $\$ 43.7$ million for all of the labor costs associated with operating the FCTP (USCTA, 1997).

The FAA continued to conduct BCAs on all of the towers operating under the FCTP to see if their current traffic and operations warranted their continued operation under APO 90-7's discontinuance criteria. As the B-C ratio was largely 
driven by traffic counts, any fluctuations in traffic caused by macro-economic conditions, local economic conditions such as the closing of a flight school, or other factors could result in an airport's B-C ratio falling below 1.0 in 1 year and the bouncing above 1.0 in the next. This posed a programmatic problem for the FAA (i.e., Ending contract operations and then restarting them the next year) that the USCTA and Congress would address.

\subsection{The cost-share program}

Beginning in 1997, many local communities began to see decreases in the level of operations at their airports. The FAA notified 22 airports that their funding for continued operations would be withdrawn because their $\mathrm{B}-\mathrm{C}$ ratios had fallen below 1.0. The USCTA argued that the FAA's BCA process was inadequate because it did not include important economic benefits including local job creation and growth in local economic activity (USCTA, 1997, 2000). Additionally, many local airport officials did not understand the BCA model and the process that controlled the flow of funding to their communities (USCTA, 1997). Several members of Congress including Former Chairman of the Senate Commerce Committee Senator John McCain (R-AZ), Former Chairman of the House Aviation Subcommittee Representative John Duncan (R-TN), and Former Chairman of the Senate Transportation Appropriations Subcommittee Senator Richard Shelby (R-AL) questioned FAA executives and wrote letters to the agency asking that funding not be withdrawn from airports whose $\mathrm{B}-\mathrm{C}$ ratio had fallen below 1.0 and also that the agency to explore a cost-sharing arrangement with local airports to continue the operation of the tower (USCTA, 1997).

In November 1997, Senator Wendell Ford (D-KY) introduced legislation that would have crated a cost-sharing pilot program for airports (both new applicants and those already in the program) whose $\mathrm{B}-\mathrm{C}$ ratio was below 1.0. A cost-share program would give the local airport sponsor the option of paying for the portion of costs that exceeded the benefits of the tower if the level of traffic decreased at an airport. For example, under the cost-share program, if an airport had a B-C ratio of .90 , the FAA would pay $90 \%$ of the costs of operating the tower while the local airport authority or sponsor would pay the remaining 10\%. While Senator Ford's legislation was not reported out of committee, The Department of Transportation and Related Agencies Appropriations Bill of 1999 (P.L. 105-249) contained a $\$ 6$ million appropriation to continue the operation of towers whose B-C fell below 1.0. Additionally, the Act's conference report contained language that directed the FAA to continue contract tower operations (via the cost-share program) at specific airports regardless of the B-C ratio (P.L. 105-249 Conference Report). Although 
the appropriation was secured for the cost-share program, an authorization was needed to codify the specific elements of the newly created program. The Wendell H. Ford Aviation Investment and Reform Act for the 21st Century (P.L. 106-181) created the requirements of the Cost-Sharing Program on April 5, 2000.

Importantly, a cost-share program would make it extremely difficult for the FAA to optimize its program expenditures by mandating that the agency had to pay a portion of the contract costs associated with operating non cost-beneficial towers. Specifically, the funding for the FCTP comes from the FAA's operations account, which funds most personnel at the agency including unionized FAA controllers. There was tension mounting within the agency's unionized controller workforce around using operations account funds to pay for mostly nonunion contract controllers, particularly as the DOT-IG, and members of Congress argued for the further conversion of more low-level FAA towers to contract towers (USCTA, 1999, 2003).

Finally, many analysts within the FAA argued that funding a pro-rata share of the operation of a tower that was not cost-beneficial was a violation of good economic practice. Economists argue that having the local community pay the portion of the costs that exceed the benefits is an example of an economic transfer from the local to federal level and does not subsequently make a project cost-beneficial (OMB Circular A-94). Additionally, the Department of Transportation's guidance on BCA (DOT, 2003) notes that agencies should not include indirect benefits of infrastructure projects or operational programs in BCAs as these are classified by OMB Circular A-94 and scholars (Lee, 2005) as economic transfers and should not be considered in decisions related to federal infrastructure or program decisions. More importantly, the funding of a portion of the costs to make the tower costbeneficial does not address the fundamental economic question from the agency's perspective-Does the tower provide enough direct benefits (safety and efficiency benefits related to the mission of the FAA) to justify the federal investment in the continued operation of the tower? While the cost-share program is an innovative way to prevent the possible closing of a tower due to an anomalous decrease in operations, the cost-share program directs the FAA to spend increasingly scarce budgetary resources on towers that are not cost-beneficial to society from a federal perspective.

\subsection{The continued growth of the FCTP}

In 2000, Congress directed the DOT-IG conducted an audit of the FCTP to examine the cost-savings associated with using contract controller labor versus FAA-controller labor at air traffic control facilities. The DOT-IG found that in FY 1999, 


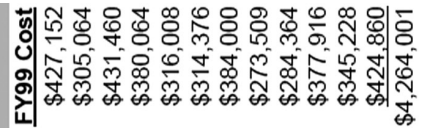

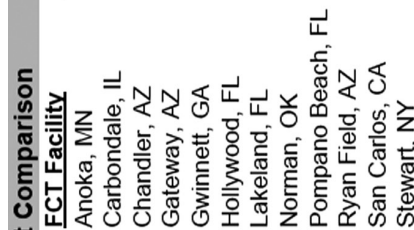

ठํํำ

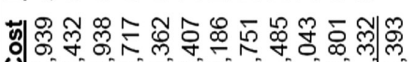

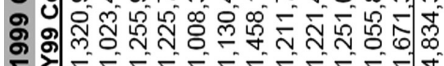

خ

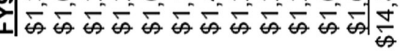

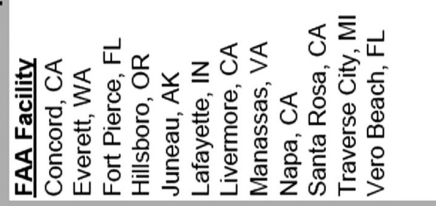

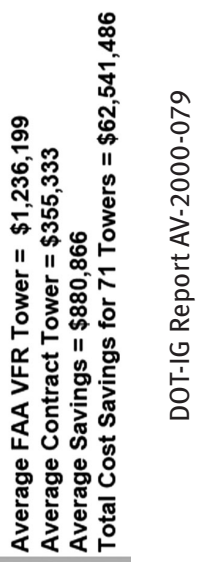

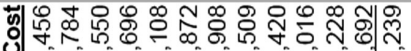

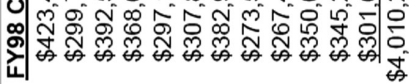

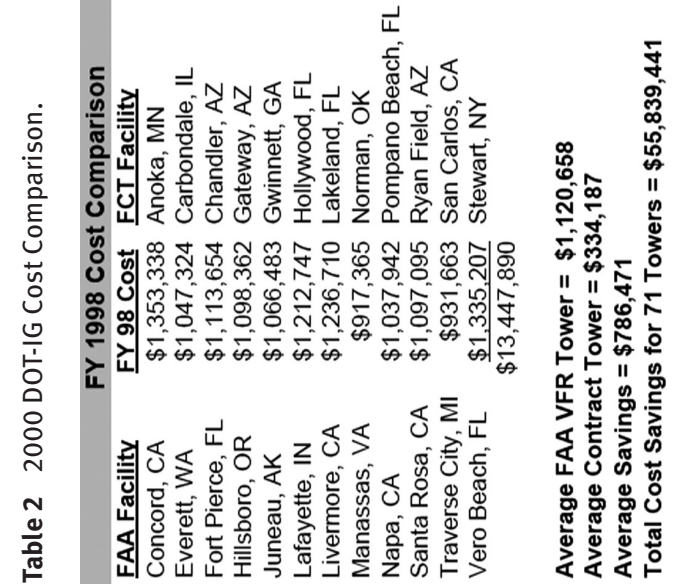


when compared with similar FAA VFR towers, contract towers were approximately $\$ 900,000$ per tower less expensive to operate. The report also found that if the remaining 71 FAA operated VFR towers were contracted out; it would save the FAA \$62.5 million annually. The main reason for the costliness of FAA towers is that FAA-controllers are paid based on a variation of the Civil Service pay scale that is collectively bargained and that FAA-staffing requirements dictate that more controllers must be on duty when compared to a contract tower (DOT-IG Report AV-2000-079). By requiring the DOT-IG to examine the FCTP in relation to FAA-staffed towers (rather than on their own merit), they helped to create a narrative that did not focus on whether a tower was needed at an airport or if it was societally cost-beneficial, but rather given that the tower is there, how much money does it save the government compared to a similar FAA tower.

One of the major barriers for airports in smaller communities who wanted to submit an application for a tower to either replace an existing structure or to build a new tower was that the FAA was authorized to spend money on the contract controller labor, but not to build a new control tower facility. On February 20, 2003, Congress passed the Department of Transportation and Related Agencies Appropriations Act of 2003 (P.L. 108-7), which contained provisions making the construction and/or equipage of airport tr affic control towers eligible under the Airport Improvement Program (AIP) if the towers built would qualify for the FCTP using the FAA's BCA guidance (FAA Program Guidance Letter 03-3). Initially, the AIP amount was capped at $\$ 1.5$ million, but was raised to $\$ 2$ million in 2012 by the FAA Modernization and Reform Act of 2012 (P.L. 112-95). Although airport sponsors in smaller communities had a financing mechanism for the construction of new towers, the inclusion of \$1.5-\$2 million in construction costs into the BCA would make it difficult to achieve the 1.0 threshold due to the low levels of traffic at many of these airports. Additionally, many local communities without towers at their airports had invested local capital dollars into the construction of new towers.

The USCTA began a series of meetings with officials at the FAA and with members of Congress to discuss an approach that would allow airports that had invested local dollars in the construction of new towers to exclude those sunk costs from $\mathrm{B}-\mathrm{C}$ ratios. FAA regulations stated that costs associated with the construction of a tower that were incurred after the community applied for entry into the Contract Tower Program should be included in the BCA (14 CFR 170). However, there were no requirements for the agency to include construction costs borne by the local community before their application to the FCTP (although economic practice would include both local and federal capital expenditures in a BCA). Senior executives at the FAA and the USCTA agreed to "grandfather" a list of communities who had began construction on towers using local funds that would be excluded from having their construction costs included in the BCA. 
Table 2 The Growth of the FCTP (1999-2012).

\begin{tabular}{rrrrrrr}
\hline Year & $\begin{array}{r}\text { FCTP } \\
\text { Contract } \\
\text { Towers }\end{array}$ & $\begin{array}{r}\text { Cost-Share } \\
\text { Towers }\end{array}$ & $\begin{array}{r}\text { Contract } \\
\text { Tower Ops }\end{array}$ & $\begin{array}{r}\text { Contract } \\
\text { Tower Ops } \\
\text { Per Tower }\end{array}$ & $\begin{array}{r}\text { FCTP } \\
\text { Funding (in } \\
\text { millions) }\end{array}$ & $\begin{array}{r}\text { Cost-Share } \\
\text { Funding (in } \\
\text { millions) }\end{array}$ \\
\hline 1999 & 186 & 0 & $18,991,627$ & 102,106 & $\$ 47.3$ & N/A \\
2000 & 199 & 0 & $19,727,960$ & 99,135 & $\$ 50.0$ & $\$ 5.0$ \\
2001 & 206 & 10 & $19,115,831$ & 92,795 & $\$ 55.3$ & $\$ 5.0$ \\
2002 & 219 & 18 & $19,343,790$ & 88,328 & $\$ 70.5$ & $\$ 6.0$ \\
2003 & 219 & 30 & $18,514,967$ & 84,543 & $\$ 78.0$ & $\$ 6.0$ \\
2004 & 226 & 24 & $18,467,130$ & 81,713 & $\$ 80.0$ & $\$ 7.0$ \\
2005 & 231 & 33 & $18,244,307$ & 78,980 & $\$ 86.0$ & $\$ 7.0$ \\
2006 & 233 & 26 & $18,111,558$ & 77,732 & $\$ 90.5$ & $\$ 7.5$ \\
2007 & 239 & 32 & $18,263,323$ & 76,416 & $\$ 97.5$ & $\$ 8.0$ \\
2008 & 242 & 16 & $16,916,866$ & 69,904 & $\$ 103.0$ & $\$ 8.5$ \\
2009 & 245 & 16 & $14,997,481$ & 61,214 & $\$ 110.0$ & $\$ 9.5$ \\
2010 & 246 & 16 & $14,117,383$ & 57,388 & $\$ 116.7$ & $\$ 9.5$ \\
2011 & 248 & 16 & $13,903,105$ & 56,061 & $\$ 111.0$ & $\$ 9.5$ \\
2012 & 250 & 16 & $13,898,368$ & 55,593 & $\$ 117.3$ & $\$ 10.3$ \\
\hline
\end{tabular}

Source: USCTA Annual Reports (1997-2011) and FAA TAF (1997-2012).

The growth of the FCTP program due to requests for new towers by Congressional delegations and local airports coupled with the overall decline in contract tower operations since 2001 has brought into question the overall effectiveness of the FCTP. Table 2 illustrates the growth of the FCTP since 1999, the overall decrease in operations at these airports since 2001, and the increase in spending on the program. Specifically, as the overall funding for the program has increased due to increased numbers of towers, increased labor costs, etc., the number of operations per tower has decreased from 102,000 in 1999 to roughly 56,000 in 2012. This indicates that Congress is directing the FAA to spend more money on air traffic control towers that are handling less aircraft on an annual basis. While the FCTP may be more efficient than a FAA-staffed tower, it remains unclear whether the program as a whole is cost-effective.

\subsection{Recent changes to the BCA process: The $20 \%$ cap and the 18-month grace period}

Following the economic collapse in 2008, the FAA decided not to release new B-C ratios because of the large number of local communities that would enter the CostShare program due to increased labor costs coupled with decreased operations 
at several airports. Therefore, the $\mathrm{B}-\mathrm{C}$ ratios currently being implemented were last calculated for fully funded towers in 2006 and for Cost-Share towers in 2008. During the interim, the FAA had also developed an advanced cost-accounting system that allowed the agency to track site-specific operations and maintenance (O\&M) costs for each contract tower that had FAA owned or maintained equipment including radar. Also, the FAA has considered reissuing new $\mathrm{B}-\mathrm{C}$ ratios that take into account a broader array of societal costs (House of Representatives Committee on Transportation and Infrastructure Hearing, 7/18/2012) associated with operating a contract tower including depreciation of FAA assets and agency overhead (FAA FCTP Stakeholder Briefing May 2012). The effect of including these costs in the BCA calculation (estimated at roughly $\$ 173,000$ on average per tower) would be to shift a number of towers into the Cost-Share program where they would be responsible for tens of thousands of dollars to continue the operation of the tower.

In order to shield its members against increased costs, the USCTA advocated for a percentage cap on the amount of money to be paid by the local community if a tower fell into the Cost-Share program. In 2009, the USCTA developed a position paper that recommended the elimination of regular BCA for towers who were fully funded by the FAA unless there was a $30 \%$ decrease in annual operations (USCTA, 2009). Specifically, the USCTA argued that the FCTP was the only services contract that the FAA used BCA to evaluate and that the FAA's BCA model omitted important local economic development benefits. While members of Congress were eager to find a solution that saved their communities money, the USCTA proposal to eliminate BCAs altogether received little traction among members of Congress. In February of 2011, Senator Mark Pryor (D-AR) successfully championed an amendment to the Senate FAA reauthorization bill that capped the local contribution at $20 \%$. In the past, if a local community had a B-C ratio of 0.60 , the local community would pay $40 \%$ of the controller labor costs while the FAA would pay $60 \%$. With the $20 \%$ cap, an airport with a B-C ratio of 0.60 would pay $20 \%$ while the FAA would pay $80 \%$. Senator Pryor championed the amendment because an airport the town of Rogers, Arkansas would have had to pay $45 \%$ of the operating costs of the tower due to the decrease in traffic associated with the economic downturn (Pryor, 2011). Before the FAA Reauthorization bill was completed, Congress passed the Consolidated and Further Continuing Appropriations Act of 2012 (P.L. 112-55), which contained the Pryor provision that capped local contributions to the Cost-Share program at $20 \%$. Additionally, the FAA Modernization and Reform Act of 2012 (P.L. 112-95) created an 18-month grace period for local contributions to the Cost-Share program, which would allow airport sponsors to better budget for any local contributions needed if their B-C ratio fell below 1.0. 
Given the extreme economic situation facing the US and provisions of the Budget Control Act of 2011, the Obama Administration's OMB initially proposed to make significant changes to the FCTP that would cut all funding for airports that did not have commercial airline service or 10,000 annual military operations (USCTA, 2011). These operations thresholds indicated that OMB was trying to cut what it viewed as a subsidy to general and business aviation operations Additionally, the FY 2013 President's Budget contained a provision that would have raised the cost-share cap from $20 \%$ to $50 \%$. These proposals by OMB and the FAA were met with opposition by Congress and the USCTA. Former House Transportation and Infrastructure Committee Chairman John Mica (R-FL) noted that while he was sympathetic to OMB's challenge in meeting budget targets set under the Budget Control Act, he directed OMB to focus its cost-cutting on programs that were inefficient and not cost-effective (USCTA, 2011). In response to OMB proposals and the FAA's plan to incorporate more costs in the re-calculation of $\mathrm{B}-\mathrm{C}$ ratios, the House Appropriations Committee noted:

The Committee is concerned that the current effort by FAA to update cost-benefit information may not fully take into account the broad array of benefits the program provides to individual communities, including enhanced safety, cost savings, and economic development. The Committee notes that FAA's updated cost-benefit calculations could reduce federal funding obligations and shift significant costs to local communities that have little if any ability to absorb additional costs. The Committee directs, prior to releasing or acting upon updated cost-benefit data, the FAA to seek input from affected local airports. The FAA should also provide a report to the Committees on Appropriations on the rationale for the cost-benefit changes, and the economic impact to affected airports prior to acting on any updated calculations (Department of Transportation and Related Agencies Appropriations Bill Conference Report, 2013).

The language in the Department of Transportation and Related Agencies Appropriations Bill conference report illustrates the degree to which members of Congress were unsatisfied with the FAA's BCA process. Specifically, the $20 \%$ cap on local cost-shares was a reaction to the fact that the FAA's BCA process did not take into account local economic benefits such as job creation. It remains to be seen whether Congress will make additional modifications to the FAA's BCA process.

Following the enactment of sequestration, on March 1, 2013, the FAA announced that it would cease funding to 173 federal contract towers in order to allow the agency to achieve $\$ 633$ million in necessary cost reductions (Elias, 2013). Interestingly, the FAA did not rely on its $\mathrm{B}-\mathrm{C}$ ratios to determine which towers to close, but instead relied on operational thresholds: towers with fewer than 150,000 total operations or fewer than 10,000 commercial operations would 
be closed. The operational thresholds were similar to those proposed by OMB in an earlier proposal to limit the FCTP due to the perception that the program was a subsidy to business aviation interests. In response to the proposed closure of the 173 towers, the FAA and the Department of Transportation received over 100 letters from members of Congress touting the need to continue funding to the towers in their districts (Bogardus and Liang, 2013). On March 22, 2013, the FAA granted 24 national interest exemptions for towers that provide critical military or national safety services. During the interim, Senator Jerry Moran (R-KS) and Senator Richard Blumenthal (D-CT) introduced amendments and legislation to give the FAA the flexibility to shift money from its other accounts (namely, the Airport Improvement Program, which is used to fund airport infrastructure improvement projects) to continue funding the operations of the FCTP. In another illustration of the wide-reaching impact of the FCTP, Congress passed the Reducing Flight Delays Act of 2013 to allow the FAA to shift over \$250 million from the AIP account to its operations account to continue funding the FCTP and operations at small FAA-operated towers. Given the Obama Administration's targeting of the FCTP for sequestration cuts and the possible release of new B-C ratios that shift more costs to local communities, the future of the FCTP remains unclear.

\section{Discussion}

The case study of the FCTP provides an interesting example of the nuanced way in which members of Congress can affect the BCA processes of agencies to direct particularized benefits (Mayhew, 1974) to their districts. There are two distinct processes at work in the case study of the FCTP: first, Congress's desire to modify the FAA's BCA process to expand the number of contract towers in order to provide tangible benefits through infrastructure projects and local jobs, particularly in smaller communities and second, to maintain the infrastructure and local jobs in the face of economic uncertainty to avoid being viewed as the person responsible for the loss of these benefits. The result of both of these efforts has been to limit the discretion of the FAA in implementing the FCTP and to mandate economic inefficiencies (i.e. the local cost-share) into the program.

Beginning in 1987 with the decision to direct the FAA to modify its BCA process to include traffic density without consideration of the size of based aircraft, Congress acted to expand the FCTP. By requiring the FAA not to consider the size of aircraft in traffic density inputs to the BCA, Congress directed the FAA to give more weight to the number of operations at an airport regardless of the number of people being served. This modification allowed members of Congress 
who represented smaller airports serving mostly general or business aviation to request that new contract towers be constructed in their communities. This led some in the FAA to note that Congress was telling the agency to use BCA to justify conversion on one hand and telling the agency to ignore the BCA process for Congressional requests on the other hand. Also, the effort by members of Congress and the USCTA to convince the FAA not to include capital construction costs for new towers in the BCA is further evidence of the desire to expand the FCTP. These findings build on Lee's (2005) assertion that members of Congress will use BCA to justify infrastructure projects and program operations by illustrating that through modifications to BCA through authorization and appropriations legislation, members can ensure favorable policy outcomes.

The growth of the contract tower program from 27 towers in 1992 to 250 towers in 2012 is staggering. Following the Clinton Administration's recommendation in 1993 to expand the FCTP, members of Congress were successfully able to advocate for 50 new contract towers between 1993 and 1995. This supports the work of Bertelli and Grose (2009) who found that distributive projects were most likely to be provided to members of Congress where there is ideological congruence on policy issues between the Administration and Congress. With towers in 48 of 50 states, the FCTP seems to provide evidence to support Shepsle and Weingast's (1981) assertion that following initial resistance to projects with geographically concentrated benefits and diffuse costs, that members of Congress engage reciprocal behavior, leading to the quasi-universalistic nature of the projects. Additionally, the ability of Congress to develop a legislative solution with bipartisan support to stop the FAA from cutting funding to the FCTP as a result of sequestration provides further evidence of the quasi-universalistic nature of the program. The growth of the FCTP is similar to the growth in other distributive aviation programs including the Essential Air Service (EAS) program, which provides subsidies for air carriers to fly into smaller rural markets that do not have the population or economic activity to justify the service. As Cunningham and Eckard (1987) note, Congressional modification of statute and program requirements, as was the case in the FCTP, led to the drastic expansion of the EAS program.

While Congress's influence in the BCA process to ensure the growth of the program has been impressive, its ability to safeguard the continued operation of existing towers through modifications to the BCA process has been more significant. Beginning with the creation of the Cost-Share program in 1999, Congress has gone to great lengths to ensure that towers operating under the FCTP remain open, even if a BCA determines that those contract towers are not cost-beneficial to society (by place-marking a tower to remain open, Congress was in fact altering the BCA process). Congress continued the safeguarding of contract towers by limiting the amount of local contribution under the Cost-Share program to 
$20 \%$, regardless of how non cost-beneficial a tower may be. This finding expands upon the work of DelRossi and Inman (1999) by providing further evidence that as the local contribution for an infrastructure project increases, the benefit to the member of Congress wanes. Additionally, by requiring the DOT-IG to evaluate the FCTP to comparable FAA-towers rather than on its own merits, members of Congress were able to create a narrative that focused on the cost of operating a contract tower versus the cost of operating an FAA tower rather than examining the overall costs and benefits of the FCTP. The narrative of the FCTP as a "successful government partnership program" led to the further conversion of FAA towers while insulating the existing towers from efforts by the agency to eliminate funding for towers that were not cost-beneficial.

Finally, as the FAA was discussing the inclusion of new costs in the BCA, Congress proactively imposed a new reporting requirement on the agency in an appropriations bill that directs the agency to explain to Congress the rationale for the cost-benefit changes and the economic impact to affected airports prior to acting on any updated calculations. This analysis supports and expands upon the work of Posner (2001) and Shapiro and Morrall (2012) who note that agency BCA processes are not designed to ensure the efficiency of regulations or programs, but rather to ensure control of agency decision-making. The legislative and administrative actions of Congress in the case of the FCTP have had the effect of limiting the discretion of the agency to optimize the efficiency of the program by requiring the FAA to spend increasingly scarce agency resources on maintaining and operating towers whose level of traffic and $\mathrm{B}-\mathrm{C}$ ratio does not support continued operation.

\section{Conclusion}

Congress's ability to substantively change the FAA's BCA process for the FCTP has resulted in an explosion of the number of contract towers across the country as members seek to provide tangible particularized benefits via infrastructure projects and jobs to their districts. While the majority of these contract towers add measurable safety and efficiency benefits to the National Airspace System (NAS) while operating more cost-effectively than comparable FAA-staffed towers, changes to the BCA process made by Congress through legislation have limited the discretion of the FAA in optimizing the program. This paper makes a contribution to the literature on Congressional delegation and particularized benefits by illustrating the nuanced way by which members of Congress can modify agency BCA processes to justify, advocate for, and protect particularized infrastructure projects. Congress' involvement in the BCA practices of the FAA's FCTP has led 
to the explosion of the number of contract towers while also limiting the ability of the FAA to optimize the effectiveness of the program by eliminating towers that are not cost-beneficial. Also, this study has expanded the scope of studies of BCA from a focus on RIAs to examining the use of the analytical tool in justifying infrastructure projects and operational programs. Future work in this area could focus on a quantitative analysis of how specific changes to the BCA process have affected the FAA's spending on the FCTP. Additionally, future work could also examine a comparative case study across agencies to investigate how Congress influences BCA processes in different agencies.

Previously published online September 9, 2013

\section{Appendix A}

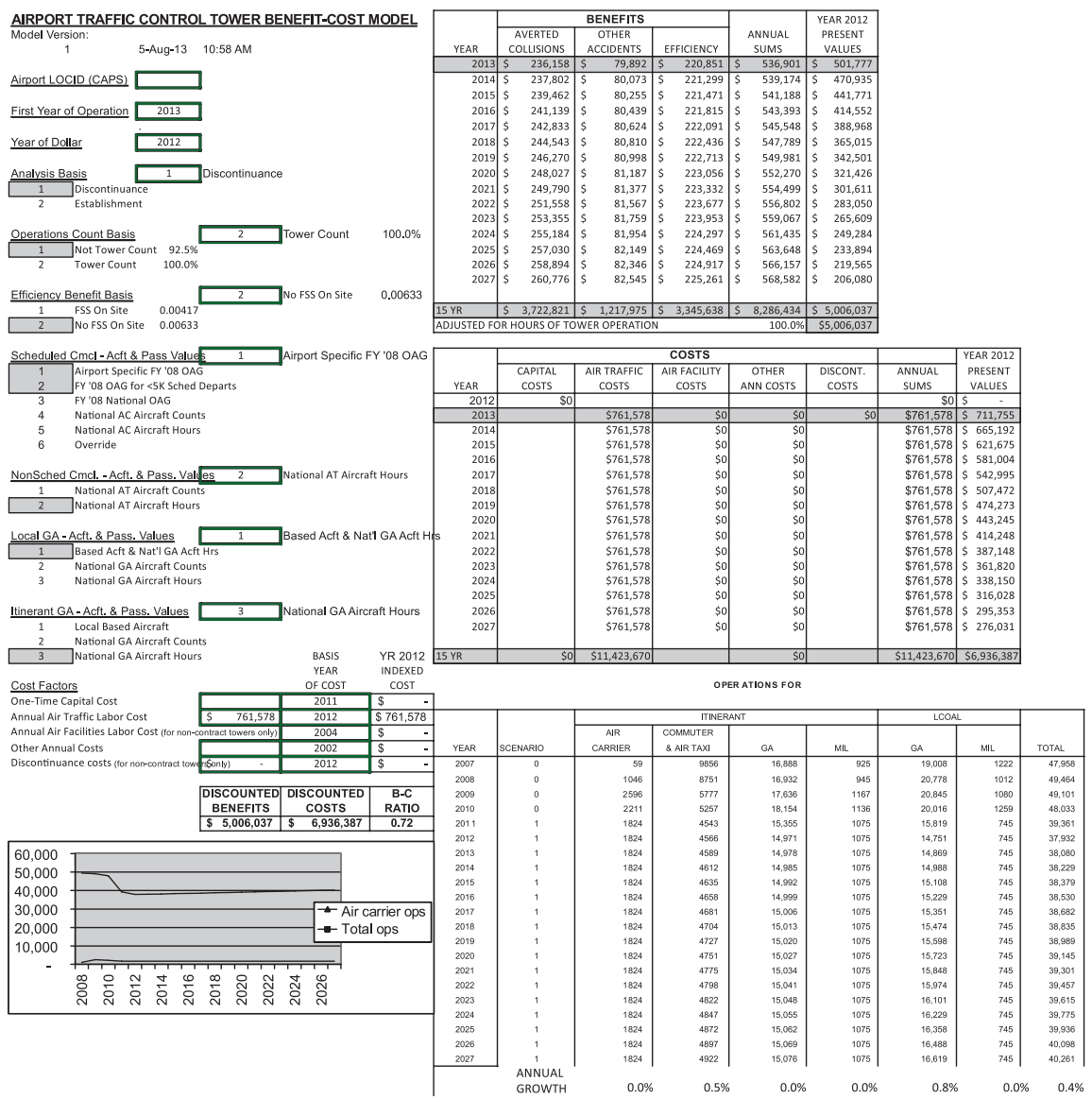




\section{References}

Aberbach, J. D. (1990). Keeping a watchful eye: The politics of congressional oversight. Washington, DC: Brookings Institution.

Alston, L. (2005). The case for case studies in political economy. The Political Economist. APSA Newsletter.

Arnold, D. (1979). Congress and the bureaucracy: A theory of influence. New Haven, CT: Yale University Press.

Bertelli, A., \& Grose, C. (2009). Secretaries of pork? a new theory of distributive public policy. The Journal of Politics, 71(3), 926-945.

Bickers, K. N., \& Stein, R. M. (1994a). Universalism and the electoral connection: A test and some doubts. Political Research Quarterly, 47, 295.

Bickers, K. N., \& Stein, R. M. (1996). The electoral dynamics of the federal pork barrel. American Journal of Political Science, 40, 1300-1326.

Carpenter, D., \& Krause, G. (2011). Reputation and public administration. Public Administration Review, 72(1), 26-32.

Copp, D. (1987). The justice and rationale of cost-benefit analysis. Theory and Decision, 23, 65-87.

Cunningham, L., \& Eckard, E. W. (1987). US small community air service subsidies: Essential or superfluous?. Journal of Transport Economics and Policy, 21(3), 255-277.

DelRossi, A., \& Inman, R. (1999). Changing the price of pork: The impact of local cost sharing on legislators' demands for distributive public goods. Journal of Public Economics, 71, 247-273.

Ellig, J., McLaughlin, P. A., \& Morrall III, J. F. (2012). Continuity, change, and priorities: The quality and use of regulatory analysis across US administrations. Regulation and Govermance, 7(2), 153-173.

Epstein, D., \& O'Halloran, S. (1999). Delegating powers: A transaction cost politics approach to policy making under separate powers. Cambridge: Cambridge University Press.

Fiorina, M. (1989). Congress: The keystone of the washington establishment. New Haven, CT: Yale University Press.

Flyvbjerg, B. (2009). Survival of the unfittest: Why the worst infrastructure gets built-and what we can do about it. Oxford Review of Economic Policy, 25 (3), 344-367.

Huber, J. D., \& Shipan, C. R. (2002). Deliberate discretion: The institutional foundations of bureaucratic autonomy. New York: Cambridge University Press.

Geertz, C. (1973). Thick description: Toward an interpretive theory of culture. In M. Martin \&

L. C. McIntyre (Eds.), Readings in the philosophy of social science (pp. 213-231).

Cambridge, MA: MIT Press.

Gibbs, G. (2007). Analyzing qualitative data. London: Sage Publications.

Goldberg, M. (1998). Discount rates for government investment projects: The economic logic of OMB circular A-94. The Engineering Economist, 43(4), 290-307.

Heinzerling, L. (1998). Regulatory costs of mythic proportions, 107 Yale Law Journal.

Jensen, J., \& Rodgers, R. (2001). Cumulating the intellectual gold of case study research. Public Administration Review, 61(2), 235-246.

Johnson, B. (1989). OMB budget examiner and the congressional budget process. Public Budgeting and Finance, 9(1), 5-14.

Kelman, S. (1981). Regulating america, regulating sweden: A comparative study of occupational safety and health policy. Cambridge, MA: MIT Press. 
Kerwin, C., \& Furlong, S. (2011). Rulemaking: How government agencies write law and make policy. Thousand Oaks, CA: CQ Press.

Kiewiet, D. R., \& McCubbins, M. D. (1991). The logic of delegation. Chicago, IL: University of Chicago Press.

Kochtcheeva, L. V. (2009). Administrative discretion and environmental regulation: Agency substantive rules and court decisions in US air and water quality policies. Review of Policy Research, 26(3), 241-265.

Krause, G. (2010). Legislative delegation of authority to bureaucratic agencies. In R. F. Durant (Ed.), The oxford handbook of american bureaucracy. New York: Oxford University Press.

Landau, S., \& Weisbrod, G. (2009). Practices for Preparing Airport Improvement Program 4 Benefit-Cost Analyses, ACRP Synthesis of Airport Practice, S03-05, Airport Cooperative Research Program, Transportation Research Board.

Lee, D. B. (2005). Methods for evaluation of transportation projects in the USA. Transport Policy, 7, 41-50.

Lowi, T. (1964). American business, public policy, case studies, and political theory. World Politics, 16(4), 677-715.

MacDonald, J. A. (2010). Limitation riders and congressional influence over bureaucratic policy decisions. American Political Science Review, 104 (November), 766-782.

Mayhew, D. (1974). Congress: the electoral connection. New Haven, CT: Yale University Press.

McCubbins, M. (1999). Abdication or Delegation? congress, the bureaucracy, and the delegation dilemma. Regulation, 22(2), 30-37.

McCubbins, M., \& Schwartz, T. (1984). Congressional oversight overlooked: Police patrols vs. fire alarms. American Journal of Political Science, 21(1), 165-179.

McCubbins, M., Noll, R., \& Weingast, B. (1987). Administrative procedures as instruments of political control. Journal of Law, Economics, and Organization, 3, 243-277.

McGarity, T. O. (1991). reinventing regulation: The role of regulatory analysis in the federal bureaucracy. Cambridge: Cambridge University press.

Moe, T. (1989). The politics of bureaucratic structure. In J. E. Chubb \& P. E. Peterson (Eds.), Can the Government Govern? Washington, DC: Brookings Institution.

National Air Traffic Controllers Association vs. U.S. Department of Transportation, Jane Garvey. 2011. United States Court of Appeals, $6^{\text {th }}$ Circuit. 16 August.

Porter, T. (1996). The rise of cost-benefit rationality as solution to a political problem of distrust. presented at the Benefit-Cost Analysis Conference May 18.

Posner, E. A. (2001). Controlling agencies with cost-benefit analysis: A positive political theory perspective. University of Chicago Law Review, 68, 1-51.

Pryor, S. M. (2011). Press release. Retrieved from: http://www.pryor.senate.gov/public/index.cfm

Revesz, R., \& Livermore, M.A. (2008). Retaking Rationality: How cost-benefit analysis can better protect the environment and our health. New York: Oxford University Press.

Sen, A. K. (2000). The discipline of cost-benefit analysis. Journal of Legal Studies, 29(S2), 931-952.

Shapiro, S., \& Morrall III, J. F. (2012). The triumph of regulatory politics. Benefit-cost analysis and political salience. Regulation and Governance, 6(2), 189-206.

Shepsle, K., \& Weingast B. R. (1981). Political preferences for the pork barrel: A generalization. Journal of Political Science, 25(1), 96-111.

Sunstein, C. (2011). Empirically formed regulation. University of Chicago Law Review, 78(4), 1349-1429.

Tomkin, S. L. (1998). Inside OMB: Politics and process in the president's budget office. M.E. sharpe. 
United States Congress. House of Representatives. Committee on Transportation and Infrastructure. 2012. A Review of the FAA's Contract Tower Program. 112th Congress. 2nd Session. 18 July.

United States Congress. House of Representatives. Appropriations Committee. 2013.

Department of Transportation and Related Agencies Appropriations Bill Conference Report.

United States Congressional Research Service. Federal Rulemaking: The Role of the Office of Information and Regulatory Affairs. 7-5700. June 9, 2009.

United States Congressional Research Service. Proposed Cuts to Air Traffic Control Towers Under Budget Sequestration: Background and Considerations for Congress. R43021. 2013.

United States Contract Tower Association. Annual report 1997. Retrieved from http://www. contracttower.org/annual.html.

United States Contract Tower Association. Annual report 1999. Retrieved from http://www. contracttower.org/annual.html.

United States Contract Tower Association. Annual report 2000. Retrieved from http://www. contracttower.org/annual.html.

United States Contract Tower Association. Annual report 2003. Retrieved from http://www. contracttower.org/annual.html.

United States Contract Tower Association. Annual report 2007. Retrieved from http://www. contracttower.org/annual.html.

United States Contract Tower Association. Annual report 2009. Retrieved from http://www. contracttower.org/annual.html.

United States Contract Tower Association. Annual report 2011. Retrieved from http://www. contracttower.org/annual.html.

United States Department of transportation. Memorandum: FAA's Contract Tower Program. 1986.

United States Department of Transportation. Economic Analysis Primer:Annual report 2003. Retrieved from http://www.fhwa.dot.gov/infrastructure/asstmgmt/primer00.cfm.

United States Department of Transportation Inspector General. Contract Towers: Observations on FAA's Study of Expanding the Program. Report No. AV-2000-079. April 11, 2000.

United States Department of Transportation Inspector General. Federal Contract Tower Program. Report No. AV-1998-147. May 18, 1998.

United States Federal Aviation Administration. Benefit-Cost Method for Selecting and Ranking Airport Traffic Control Tower Candidates. FAA Order ASP-75-4. 1975.

United States Federal Aviation Administration. Establishment and Discontinuance Criteria for Airport Traffic Control Towers. FAA Report APO-83-2, August 1983.

United States Federal Aviation Administration. Establishment and Discontinuance Criteria for Airport Traffic Control Towers. FAA Report APO-90-7, August 1990.

United States Federal Aviation Administration. Memorandum: FAA Contract Tower Benefit-Cost Analysis. April 23, 1992.

United States Federal Aviation Administration. FAA Federal Contract Tower Program Stakeholder Briefing. May 18, 2012.

United States Government Accountability Office. Status of FAA's Plans to Close and Contract Our Low-Activity Towers. GAO 94-265. September 12, 1994.

United States Government Accountability Office. Highlights of an Expert Panel: The Benefits and Costs of Highway and Transit Investments. GAO 05-423SP. May 2005.

United States Office of Management and Budget. Regulatory analysis. Circular A-4. 2003. 
United States Office of Management and Budget. Guidelines and discount rates for benefit-cost analysis of federal programs circular A-94. 1992.

Van Wee, B. (2012). How suitable is cba for the ex-ante evaluation of transport projects and policies? A discussion from the perspective of ethics. Transport Policy, 19, 1-7.

Weidenbaum, M. (1997). Regulatory process reform from ford to clinton. Regulation, 20(1), $1-12$.

Yackee, J. W., \& Yackee S. W. (2010). Administrative procedures and bureaucratic performance: Is federal rule-making ossified? Journal of Public Administration Research and Theory, 20(2), 261-282.

Yin, R. (2003). Case study research: Design and methods. Sage: London.

Zerbe, R. (2007). An ethical benefit-cost analysis. Working Paper. Northwestern University School of Law. 